\title{
"What happened was foremost an assault by interests of the big capital." An interview with Breda Pavlič.
}

\author{
Sašo Brlek Slaček; ; Jernej Amon Prodnik; Breda Pavlič.
}

* Social Communication Research Centre, Faculty of Social Sciences, University of Ljubljana, Slovenia, saso.brlek-slacek@fdv.uni-lj.si, jernej.amon-prodnik@fdv.uni-lj.si

\begin{abstract}
Interview with Breda Pavlič, critical researcher and former staff member of UNESCO's Division of Free Flow of Information and Communication Policies in the 1980s (1984-1989). We discussed her path towards the critical-analysis approach to information and communication problems, the role of such analyses in the academic field of the time, as well as within the political context of the Movement of Non-Aligned Countries, and their initiative in UNESCO and in the United Nations Organization for a New international information and communication order (NIICO).
\end{abstract}

Keywords: Unesco, New International Information and Communication Order, Non-Aligned Movement, the MacBride Report, political economy of communication.

In the 1980s a major conflict took place at the highest level of international relations. Had it not been subsequently swept under the carpet, it would still be a significant event in global politics. It focused on the increasingly evident inequality between the industrially developed countries on one hand, and the so-called developing countries on the other hand, particularly their respective roles in the worldwide exchange of information, i.e., in the global flow of information via the mass media and all other means. Manifesting itself as a 'cultural imperialism' in which transnational corporations (TNCs; known also as multinational corporations, MNCs) held a dominant role, the debate about this was eventually brought to UNESCO as the UN's main body responsible for worldwide education, science, culture and communication. It culminated with the publication of the report Many Voices, One World prepared by an eminent international commission that was presided by Sean MacBride from Ireland. Published in 1980 by UNESCO, its very title - and even more so its subtitle (i.e. Towards a new more just and more efficient world information and communication order) - underlined the need to promote various development paths in order to help foremost the developing countries in building indigenous capacities in accordance with their respective populations' social and cultural needs. This vision, however, came upon immense resistance of certain governments, non-governmental organizations and private corporations, primarily from the United States and the United Kingdom, which were by then already aiming at creating a different 'unified' global framework for unobstructed market expansion of the mightiest (corporations) in the rapidly growing area of information and communication.

Breda Pavlič witnessed these events from close range. At the beginning, by cooperating with various critical communication researchers, mostly through AIERI/IAMCR [International Association for Mass Communication Research], who were first to point out the on-going economic and cultural dependence of former colonies upon their former colonial masters, especially through the rapidly growing power of transnational corporations, the increasing submission of information and communication to 
market logic, and the potentially irresponsible consequences of a worldwide spread of the mass consumption mentality. Some years later, she continued to observe these processes while working in UNESCO's Division of Free Flow of Information and Communication Policies, particularly during the key period when Ronald Reagan's administration in the US and Margaret Thatcher's government in the UK stifled ruthlessly all endeavours to create a different information and communication order. The conflict that ensued finally led the two Member States to abandon UNESCO for nearly two decades.

Breda Pavlič's concern regarding cultural imperialism, commercialization of culture and the role of TNCs in these is rooted in her early life experience, notably the four years she spent as a teen-ager in the International School in Kebajoran, i.e., in Djakarta (Indonesia), where her father was posted as diplomat. It was there that she first experienced 'the American way of life', including fast food (hamburgers, pizza, etc.), Coca-Cola, pop music and American fashion - all of which bedazzled her in the beginning. However, it also underlined more poignantly the immense gap between the poor and the wealthy, especially within context of a developing country. Later, while studying sociology at the Ljubljana University and at the Universite Libre in Brussels, which helped her understand the role of culture in colonialization (particularly certain writings in anthropology of the 1950s and 1960s) she was shocked by news of the bloody military coup that took place in Indonesia, in 1965, 'which was endorsed primarily by the US and Australia, i.e., their governments and the so-called multinational - or rather, transnational - corporations'. Beyond these events, her interest in information and communication matters was spurred further during her undergraduate studies particularly by writings of $\mathrm{C}$. Wright Mills, notably his The Power Elite, as well as Erich Fromm's The Sane Society, John Kenneth Galbraith's The Affluent Society, and many other incisive scholars.

We conducted the interview with Breda on $5^{\text {th }}$ of September, 2014, in Ljubljana. The interview was translated from Slovene to English by Breda herself.

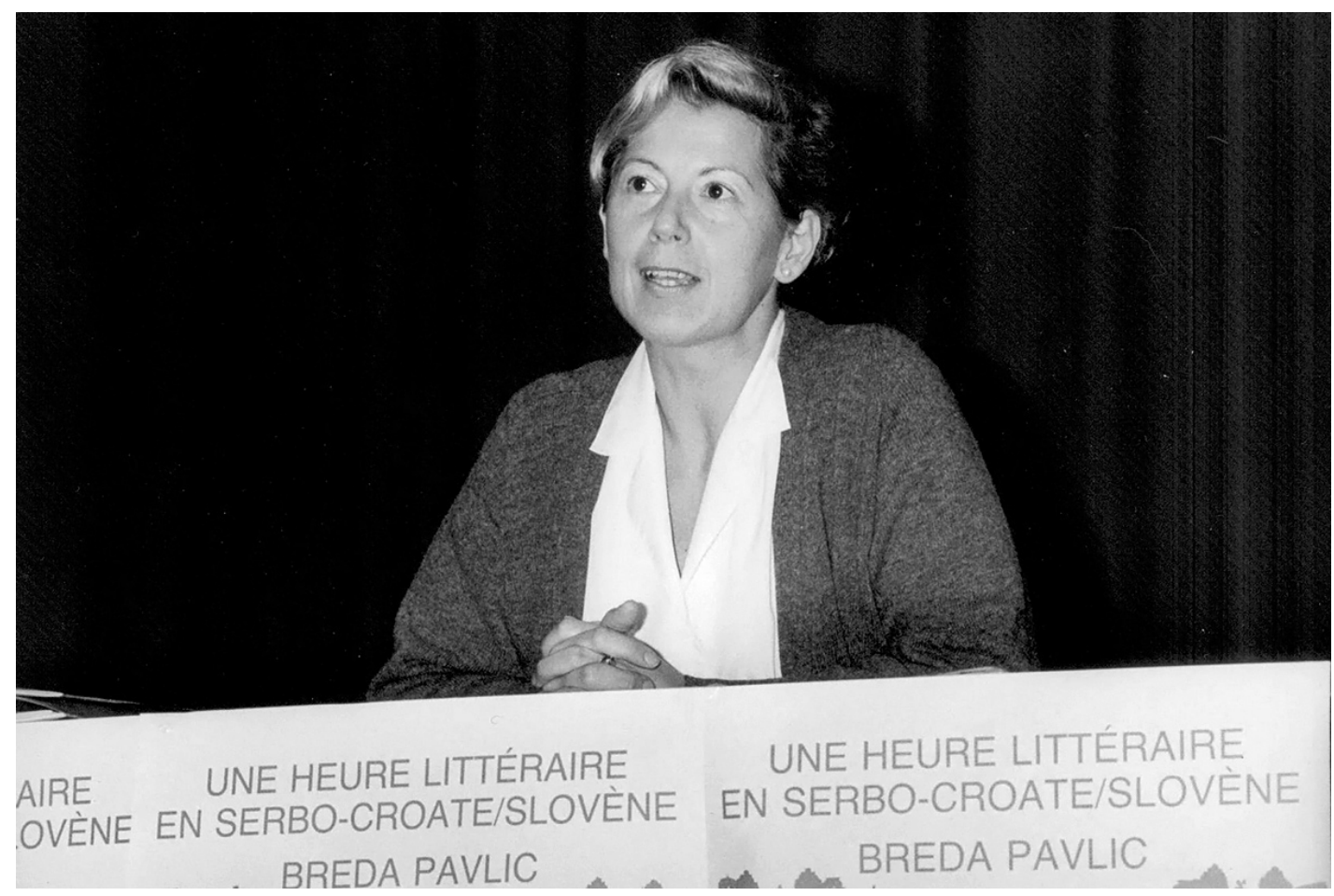

(Photo: personal archive of Breda Pavlič) 
Jernej: How did you adhere to the critical approach to communication?

Breda: Initially, Bogdan Osolnik played a very important role. By accident, or fate, Ljubljana hosted in September 1968 its first international symposium by AIERI/IAMCR, i.e., the International Association for Mass Communication Research, which was at the time the principal NGO of information-communication researchers from various parts of the world. This symposium on Mass Media and International Understanding was organized by the Faculty for Sociology, Political Sciences and Journalism (FSPN, now FDV - Faculty of Social Sciences). More specifically, the main organizers of this event - the first of its kind in former Yugoslavia - were Bogdan Osolnik, the late prof. France Vreg, and the late Tomo Martelanc. At the time I was completing my studies in sociology at the Faculty of Philosophy. Given my fluent knowledge of English, French and Srbo-Croatian, I was invited by Osolnik to help the Organizing Committee in preparing the gathering. This turned out to be a most valuable experience. My main task was to read all of the received written contributions. These came from various parts of the globe and, moreover, dealt with communication problems from different angles: anthropological, psychological, socio-political, economic/financial, etc.

The participants included a number of eminent persons, notably Jean Schwoebel (from French Le Monde), prof. Juan Beneyto from Spain, prof. Elizabeth NoelleNeumann from Germany, prof. William E. Porterand and prof. Gertrude Robinson from USA, Dinker Rao Mankekar (known editor from India), prof. Dallas W. Smythe from Canada, prof. Yassen Zassursky from Moscow, prof. Kaarle Nordenstreng from Finland - to mention but these. Among those who confirmed attendance was also the well-known prof. Herbert I. Schiller, but he unfortunately had to cancel his trip at the last moment (due to a tragic event in the family). However, considering that his paper entitled International Communictions, National Sovereignty and Domestic Insurgency was ready for distribution, and the Organizing Committee found it outstanding in many ways, the latter decided that the paper deserved to be presented also orally during one of the sessions. Since video-conferencing was not yet in use, I was asked to present Schiller's paper (somewhat shortened, by highlighting main points) on his behalf. And so, immediately after my presentation prof. Dallas Smythe - one of Schiller's long-time friends - approached to congratulate me. Thereupon he asked what my further plans were once I graduated. More specifically, would I consider going abroad - notably to Canada - for graduate studies in information-communication research? Indeed, I got two other similar proposals in the following days, one for University of Michigan (Ann Arbour) and the other for University of Washington (Seattle). Upon careful consideration I chose Canada because Smythe's scholarly approach seemed the most interesting and his university was the first to offer me enrolment in the MA programme together with a modest salary as research assistant which covered my basic livelihood. As a result, I plunged further into the critical approach to research of information and communication institutions and processes, as spearheaded at the time by Schiller, Smythe, Cees J. Hamelink, Tom Guback, Bob White and their followers (e.g., Janet Wasko, Eileen Meehan, Oscar Gandy and others).

By June 1970 I accomplished my MA in Regina by presenting successfully my thesis on The Self-Consuming Consumer Society: The Effects of Consumption upon Education in Mass Society. Following the tradition of C. Wright Mills, Erich Fromm, Thorstein Veblen and other eminent scholars, it focused on the rapidly expanding consumer society and the intense commercialization of mass media. In former Yugo- 
slavia - and in Europe at the time - mass advertisement was still in its beginning stage. Hence I was appalled by North American mass consumption, clearly spurred by omnipresent advertising in commercial media. This, in turn, revived quite unexpectedly my teen-age experience of 'the American way of life' which, as said, happened in the altogether different social and cultural setting of Indonesia in the 1950s. Taking into account the belief - especially of economists and business experts - that mass consumption and advertising are indispensable for any society's development/progress, I thus addressed in my thesis a key question: 'What is the human cost of such development, implying both the individual (personal) cost and that of a society (collective)?' In other words, with what consequences upon human and natural environment, and on the basic socio-cultural values of a society, which are meant to help educate children to respect nature and life, feel a sense of responsibility, use rationally their resources, develop feelings of solidarity with other human beings (and, indeed, with non-human beings as well), etc.? Two years later, in 1972, while working as a teaching and research assistant of prof. Vreg at FSPN, I wrote an additional, fairly comprehensive text, as second part of my Regina thesis (in order to have it recognized by University of Ljubljana) in which I focused on consumer behaviour in Yugoslavia.

Jernej: You then worked at FSPN and became actively involved in IAMCR?

Breda: Yes. From 1970 until 1980 I worked at FSPN where I obtained my Ph.D in July 1977 under scholarly guidance of the late, deeply respected prof. Vlado Benko, and as co-tutor prof. France Vreg. Thereupon I became Assistant Professor (dozent), and in 1978 I was two semesters Visiting professor in the Communications Department at the University of Illinois, Urbana-Champagne campus, where I worked primarily with prof. Tom Guback. I was even offered to continue my academic career there, but for personal and administrative reasons I decided to return to Slovenia, i.e., to FSPN. Then, two years later, by free will I switched to the Centre for co-operation with Developing Countries, led at the time by Dr. Boris Cizelj, as their programme was better suited to my research focus on developing countries and the Movement of Non-Aligned Countries. I continued, however, to honour some of my teaching assignments at FSPN, mainly tutoring graduation diploma works. Parallel to this I continued my involvement in IAMCR, where I chaired for some five years its International Communication section. This gave me the opportunity to meet many other outstanding communication researchers such as George Gerbner, Rita Cruise O'Brien, James D. Halloran, Graham Murdock, Peter Golding, Tapio Varis, Antonio Pasquali, Rafael Roncagliolo, Fernando Reyes Matta - to name but these. Among these was also my colleague prof. Slavko Splichal, with whom I shared for ten years, at FSPN, a small, cigarette-smoke-filled office. As you know, he eventually became one of the world's most respected communication researchers and, rightfully so, member of the Slovenian Academy of Science.

At the same time Bogdan Osolnik and I continued to be very active in the Yugoslav National Commission for UNESCO, and in various bodies dealing with the NonAligned Countries and the Group of 77 . The latter two represented virtually all of the so-called developing countries, i.e., the formerly colonized countries of Africa, Asia, Latin America and the Caribbean. Allow me a brief digression: It is important to underline that the very first gathering of the heads of state (or other high-ranking representatives) of these countries took place in 1955 at the remarkable Bandung Conference, in Indonesia. Organized by Indonesia's first president, the visionary Dr. Ahmed 
Sukarno, it was indeed a major historic moment: the recently decolonized nations got together for the first time to discuss their development aims and to speak up together within the United Nations Organization. (My late father, Dr. Stane Pavlič, became deeply involved in this as Yugoslavia's diplomat shortly after the Bandung event, which later spurred my own interest in this part of modern history.)

Back to what I said before this digression, let me add that Bogdan Osolnik was at the time (end of 1970s) one of the sixteen eminent members of the International Commission for the Study of Communication Problems, created by UNESCO and chaired by the Nobel Peace Laureate from Ireland, Sean MacBride. During its twoyears-long deliberations I occasionally helped Osolnik as personal assistant.

Jernej: It was at this time that you wrote together with Cees J. Hamelink a study for UNESCO, right? How did this happen?

Breda: During the 1970s the Non-Aligned Countries and the Group of 77 proposed within the UN system that a new - i.e., more just - international economic system be created throughout the world. This became known as the developing countries' request for a New International Economic Order (NIEO). By then it became increasingly evident that the former colonies of Africa, Asia, Latin America and the Caribbean despite having won independence in legal and political terms, were in fact still deeply dependent of the industrially developed countries (i.e., former masters) in economic, trade, financial, and technological regard. Moreover, many trustworthy analyses indicated that in given conditions the gap between the developed and the developing countries would become even deeper. What I have just said is, of course, a very rough sketch. There is, however, a great deal of documented literature (available in many languages) on all this. As basic reading I would recommend, for instance, The New International Economic Order: Confrontation or Co-operation between North and South?, which was edited by Karl P. Sauvant and Hajo Hasenpflug (Westview Press, 1977).

Critically oriented communication researchers such as Schiller, Smythe, Hamelink and others drew attention very soon to the deep interlinking and interdependence of any society's communication development, on one hand, and its overall economic development, on the other hand. A successful implementation of the NIEO therefore required a parallel implementation of a new international information-communication order, i.e., NIICO. The more so when one takes into account the intensive development of digital info-communication technologies and its invasion of the entire fabric of contemporary life, notably in banking, trade, production, education, security, transportation, etc. The interdependence of NIEO and NIICO was officially discussed for the first time among representatives of the Non-Aligned countries at the conference on this topic, hosted by Tunisia in February 1977, in Tunis. It was there that participants laid also the foundations of the News-agencies' Pool of Non-Aligned Countries, i.e., a network for daily exchange of news among these countries' news agencies and also other developing countries. This Pool was coordinated for many years by Tanjug - the Yugoslav news agency. In addition, the success of the Tunis conference encouraged the participating states - helped by IAMCR's researchers, notably Kaarle Nordenstreng, Tapio Varis, Rafael Roncagliolo, Bogdan Osolnik, etc. - to introduce the NIEO-NIICO interdependence debate also into UNESCO's programme.

At a more personal level I dealt with the above in my Ph.D. thesis, which focused on a critical analysis of the role of transnational corporations in the use and further development of information-communication means, particularly the mass media. 
Namely, during my five-years-long work on the thesis the world witnessed on 11th September 1973, in Chile, the bloody military coup which murdered the democratically elected President Salvador Allende and most of his government, together with tens of thousands of Chile's students, intellectuals, and other most progressive persons. This atrocious event (later known as Operation Condor) was again - as in Indonesia - sponsored by mighty transnational corporations, in this case particularly the ITT communication giant, and endorsed by the US government. In other words, by the very agents that Allende publicly denounced a year earlier in his very courageous, indeed unique, speech at the General Assembly of the United Nations.

Then, in early 1980, shortly after the UNESCO General Conference held in Belgrade (at which the MacBride Report was presented), I received an offer from UNESCO's Division of Free Flow of Information and Communication Policies (directed at the time by Hamdi Kandil, a former well-known Egyptian journalist) to write a study about the NIEO-NIICO interdependence. Accepting the offer, I immediately proposed as my co-author prof. Cees J. Hamelink from Amsterdam, as he was among the very first researchers to examine critically the role of modern informationcommunication technologies in the global flow of trade and finance, i.e., the transborder data flows, and how this augments further the already immense power of the TNCs (or MNCs). Our study was published by UNESCO in 1985, in three languages (English, French and Spanish - the Spanish version was reprinted, I was told, even twice) as The New International Economic Order: Links between Economics and Communications.

Meanwhile, in the late 1970s and early 1980s I was invited by UNESCO to several expert meetings on this (and related) subject, and had the privilege to be elected as Chair-person at one of them (Nairobi), and as Co-chair at another (Paris). And then, in Summer 1982, the Division of Free Flow informed me that a P-4 (higher-level programme officer) post was open for recruitment. Considering that its job-description corresponded largely to my own research experience I decided to apply. Naturally, the post was advertised worldwide, and there were altogether 92 candidates from various parts of the globe that applied for it. The selection process lasted for more than a year. (Beforehand, I had to go also through a similar process within Yugoslavia in order to be an 'officially endorsed candidate'.) Finally, in December 1983 I received the official letter informing me that the Director-General of UNESCO (Amadou Mahtar M'Bow) had appointed me to the post. Three months later I moved to Paris and literally dived into a very demanding assignment. My work in the communication division went on for six years (till Fall 1989), whereupon the new Director-General, Federico Mayor Zaragoza, appointed me as his representative to Canada (and Director of UNESCO's Office in Quebec), which lasted nearly four years. After that I returned to the Paris Headquarters, with challenging new assignments, first within UNESCO's World Heritage Centre, and then as Director of the Status of Women and Gender Equality programme. Thus, albeit continuing to work on truly exciting UNESCO projects, as of 1990 I was personally no longer part of the international critical information-communication research scene.

Jernej: Could you explain in more detail the activities of UNESCO's Division of Free Flow and Communication Policies at the time, when you were there?

Breda: It's been many years since, but let me sketch it roughly as I remember. In Spring 1984, when I began working in it, UNESCO had a Communication Sector (which some years later was fused with the Culture Sector), which had three pillars: 
Division of Free Flow of Information and Communication Policies, Division of Communication Development, and a somewhat more autonomous International Programme for Development of Communication (IPDC). The latter two focused on practical and technical assistance and on professional education (e.g., training of information and communication technicians, training of journalists, radio and TV personnel, etc.) in developing countries foremost. Our Division, which was headed (after $\mathrm{H}$. Kandil) by Alan Hancock, an excellent, hard-working British communication expert, focused on enhancing worldwide research in the information and communication area. Based on the decisions of UNESCO's 199 Member-States (every two years at its General Conference) and the budget allocated for each programme, our Division was responsible for implementing these and reporting back to the General Conference. Our work consisted mainly of organizing expert meetings on required topics, training seminars, production of requested studies and analyses (carried out by most competent universities and professional NGOs in various parts of the world). These were selected by strictly respecting the geo-political, cultural and gender balance.

As for my own assignments, these were from the start nothing less than explosive! I was responsible for several 'hot' files, roughly said: (a) the NIICO, and the MacBride Report; (b) the right to communicate, and (c) women and the media. Thus, just two weeks or so after taking up my job I was asked by my superiors to draft the DirectorGeneral's reply to some member of the UK parliament regarding UNESCO's position on NIICO. (My draft, of course, went through several other hands before it got its final form - and thus became a noteworthy experience of the so-called 'visa' - i.e., approval - system, which is typical of all highly hierarchical national and international bodies.) The epistolary exchange in question was indeed important in view of the US decision (i.e., of Ronald Reagan's administration) to leave UNESCO because of the latter's involvement in - or rather, endorsement of - the developing countries' promotion of a NIICO. The US government - seconded by the UK government of Margaret Thatcher - opposed vehemently all debate about NIICO, arguing that any such a 'new order' would strengthen state control of the media, and thus impede 'the free flow of information' within nations and globally. At the time, however, there was still some hope that the UK might perhaps not leave UNESCO, and that some sort of compromise could be reached. Alas, this did not happen, and so with the departure of the two Member-States (and Singapore) UNESCO lost about a third of its budget. This situation endured a long time, i.e., until the two reintegrated the Organization at the beginning of this millennium.

Briefly, in those years (until the fall of the Berlin Wall, in November 1989) the UNESCO Secretariat worked daily literally between two fires, i.e., in the conditions of perpetual Cold-War antagonizing, even conflict, between the East and the West, or rather, between the USA and the USSR. This was further aggravated by the NorthSouth confrontation, i.e., between the demands and expectations of the developing countries on one hand, and the as yet relatively covert entrenchment of the corporate, neo-colonial forces, which eventually spread globally - as one clearly sees today.

Sašo: It was at about this time that a shift in terminology occurred: the term 'international' was replaced by that of 'world'. Hence, the term New International Information and Communication Order (NIICO) became known as a New World information and Communication Order (NWICO). Could you explain what were the implications of this change? 
Breda: In my view, this change was dictated by political interest. The Non-Aligned and the Group of 77 consistently spoke of a new international order, thus emphasizing interaction between and among nations, i.e., peoples, as one means when speaking of 'international co-operation', 'international assistance', etc. In other words, these countries insisted on national sovereignty. And this, precisely, was contested by the US and most West- European countries. These argued that such an order would favour the role of the state, implying thereby that it would legitimize state control of information and the media, as was at the time true of the so-called 'Soviet model'. As defenders of 'freedom of information' - which (as one saw later) only the sacrosanct 'market' was allowed to regulate! - Western representatives staunchly opposed such terminology and seemingly acquiesced only when a compromise was reached (after long and exhausting debates within UNESCO's governing bodies). The term world was thus adopted by consensus, albeit - as it became evident later on - this modification affected also the content and further fate of the original concept. And so, one can say with hindsight, we eventually got a 'new' world order - I mean the one we have now, consisting of highly commercialized media that are controlled by 'big money' , mostly that of transnational corporations. By advocating daily the global expansion of the ruling neoliberal doctrine (as 'the only viable alternative', or rather, as an inalterable, God-given system) most of today's mass media serve in fact the on-going, planet-wide brutal exploitation of human labour and the word's natural resources.

Sašo: The free flow of information doctrine - which sort of contradicts the notion of national sovereignty that the term international information and communication order implies - is rather older, right?

Breda: Indeed. The free flow of information doctrine (re)appeared soon after the end of World War Two. It was at first a rather promising ideal, but the thorough research done by critical communication researchers in the 1960s and later revealed its deep flaws. Given the technical and economic reality of the world at the time - by this I mean foremost the by then visible gap between, on one hand, the industrially developed countries of 'the North' and 'the West', and on the other hand a multitude of industrially underdeveloped or barely developed countries - the free flow of information doctrine only deepened further the already blatant inequality among nations in the information-communication area. This led UNESCO to propose during the rather acrimonious debate concerning the MacBride Report a compromise term, notably, 'a free and balanced flow of information'.

This, however, affected considerably our Division's work. Namely, such politicoterminological compromises look well on paper, i.e., in final documents of international meetings, but are practically useless, especially in research terms. How was one to define 'a balanced flow of information' and who was to judge this? With time it thus became clear that this decision by the General Conference was in fact just a face-saving device, an honourable retreat for the Non-Aligned and other developing countries. Indeed, by then their original quest for a new, more just information and communication exchange/order among nations had been deformed beyond recognition.

Sašo: However, in 1980 the General Conference of UNESCO adopted unanimously the recommendations of the MacBride Report. 
Breda: You are right. But this was obtained through consensus. Mr. M'Bow, who was then Director-General of UNESCO, was known as a man of consensus. This was rooted in his African cultural background, in which consensus is the basis of tribal coexistence. It is known as palabra, and is used to resolve any situation of conflicting interests among members of a tribe, a village, etc. Roughly explained, it requires that each of the parties (in a conflict) relinquishes part of its demands in order to come closer to the other, and thus enable agreement that is as just for all concerned as is possible. This is in fact the essence of all honest negotiations. When applied to international documents, however, the notoriously cryptic diplomatic wording used by negotiators tends to turn these into rather complicated texts that are often quite contradictory, and are therefore difficult (if not impossible) to apply in practice. This was of course felt most keenly in UNESCO's secretariat, which was responsible for implementing the decisions of each General Conference by cooperating on specific issues with various partners, notably various universities, research institutions, NGOs, individual experts, and so forth.

Sašo: While reading the MacBride Report, in which one can indeed see traces of compromise, I was surprised by its overt advocacy of developing countries' position. It struck me as exceptionally radical when pointing out, for example, commercial censorship while attacking the 'free flow of information' doctrine.

Breda: The members of the MacBride Commission were, as you know, highly distinguished persons with rich professional experience. Their individual perceptions stemmed from profoundly realistic assessments of the world situation at the time. For example, the famous Colombian novelist-Nobel Laureate Gabriel Garcia Marquez was first a journalist. As such he knew well the situation in various countries of Latin America, which suffered at one time or another from Spanish, French, British, German, Dutch, American and Soviet interference in their respective nations' economics and politics. As you probably know, until quite recently (and esp. during the Cold War) Latin American countries were considered as 'the USA backyard' that no other power should interfere with, while the former Soviet Union treated likewise most of Eastern Europe as its 'sphere of interest'. It is therefore quite understandable that Garcia Marquez and Juan Somavia (from Chile, later excellent Director-General of ILO in Geneva) advocated the views and needs of the Latin American peoples. The same was true of some other members of the Commission, notably those from Africa and Asia.

This being said, I should add that even the views of the afore-mentioned were relatively carefully (diplomatically) expressed. According to many views from academia, especially those of AIERI/IAMCR's critical communication research, the MacBride Report in its final version was a rather watered-down document, i.e., hardly radical! This was clearly expressed in Communication in the Eighties: A Reader of the MacBride Report edited by Cees J. Hamelink. However, as already pointed out, even the published 'soft' version of the report proved to be inacceptable to the Western - and esp. the American and British - media, their corporations and their governments.

This was followed by a well-orchestrated, uncompromising attack on Mr. M'Bow personally (indeed, a classic case of dishonest, brutal character-assassination by certain media!) and on UNESCO as a whole. At the same time it was also a somewhat covert attack on the UN system, or rather, on the then principal fora of multilateral co-operation, which the US could no longer dominate and control. 
At this point it is necessary to mention also the significant role played in this attack on UNESCO by certain powerful (and wealthy) NGOs, notably the Heritage Foundation and, linked with it, the World Press Freedom Organization. Impregnated with prejudiced, indeed reactionary ideology, their representatives opposed bitterly whatever they deemed as threatening to the dominant position of global news agencies such as Reuters, Associated Press and AFP. Our Division thus had to deal frequently with the WPFO and the equally relentless International Federation of the Periodical Press, which defended above all the commercial interests of privately owned media. On the other side, however, we had to deal at that time also with the equally aggressive Soviet-controlled (including KGB) media proponents - all of which was typical for the Cold War circumstances. Fortunately, in November 1989 with the fall of the Berlin Wall we needed no longer be concerned with the Soviet/KGB presence, but the American (Heritage and other) surveillance and interference continued unimpeded

Sašo: How did journalists respond to the MacBride Report in your view? When looking through documents I was quite shocked by the denunciation campaign, which took place at the time, which systematically spread lies, some signed even by wellknown journalists, editors, journalist associations, etc. One such lie, often found, was that the Commission proposed introducing journalist licences, despite the fact that the Report explicitly states that the Commission was aware of how dangerous this would be and it therefore chose not to propose this. I was likewise shocked by how rapidly certain journalists, whose job is to report objectively, chose to serve such a dirty campaign.

Breda: On the whole, journalists worldwide were quite divided. Those adhering to IPS (Roman-based Inter-Press Service), the International Federation of Journalists, the Pool of News Agencies of the Non-Aligned Countries, and some other basically understood and supported the MacBride Report. Albeit in certain cases some might have been suspected of favouring State-controlled media. On the other side of the spectrum, however, were journalists supporting the Western concept of 'absolute freedom of information', total commercialization of the media, etc., promoted by the WPFO and other like-minded bodies. Some of these competed in quoting Mr. M'Bow (or other UNESCO representatives) and/or parts of the Report by tearing these out of context, thereby deforming what had been indeed said. Worse yet, such deformed statements were then spread widely through syndicated press networks to even the remotest parts of the US and other countries. Their readers/viewers were thus 'informed' and 'concerned' (as taxpayers) by the 'dangerous' intentions of UNESCO and its MacBride Report. And then, in turn, these tax-payers were used as alibi by their governments' representatives at UNESCO meetings for justifying their decisions to cut the Organization's funding - and ultimately even their withdrawal from UNESCO.

The conflict at the time was very bad indeed. With hindsight one understands even better the stakes on both sides. In a nutshell I would say that the assault on UNESCO and the MacBride Report was basically spurred by big-capital interests. The media and all of information \& communication being an essential instrument of economic, financial and political power, the global corporations and big-capital in general could not tolerate anyone's interference in this area. When the Non-Aligned Countries and the Group of 77 began organizing itself in this regard (the Pool, and various South-South networks of cooperation that followed) and, moreover, succeeded in influencing the UN and its agencies (UNESCO) to move in that direction, 
the corporate-big-capital powers clearly became sufficiently alarmed to stifle the process.

Jernej: This is indeed interesting. Recently I spoke with a colleague in Brussels who deals with these questions. She co-edited a book on NWICO and transition to WSIS [World Summit on the Information Society]. According to her the authors wished to present this publication also at UNESCO, but were flatly refused, supposedly because 'Whatever concerns NWICO has no place in UNESCO'. This rather extreme response strikes me as direct censorship.

Breda: Alas, things have indeed gone far. When Federico Mayor was elected Director-General of UNESCO in November 1987, our Division was asked to find a suitable solution, i.e., proposals to appease the conflict which threatened the very existence of UNESCO, i.e., all its programmes (in education, science, culture and communication). At the time it was said that Canada too might leave UNESCO (following the USA, UK and Singapore). Fortunately this did not happen, largely due to Mr. Mayor's immense effort to clarify matters with the Canadian government authorities, and their subsequent involvement in promoting policy changes from within the Organization. (I witnessed this first-hand as UNESCO's representative to Canada in 1989-1993.)

At the same time, however, one should remember that in November 1989 the Berlin Wall fell, and that changed profoundly the entire international scene. The NWICO rhetoric and programme were thus gradually dropped and substituted by UNESCO's greater focus on journalist training, technical aid to developing countries in setting up their media and other information-communication needs, etc.

Jernej: The MacBride Report is still taboo in UNESCO, right? And NWICO is hardly ever mentioned in UNESCO.

Breda: As far as I know, this is so. Today, it seems as if it never existed! It has been deleted not only from subsequent and present programme and budget, but largely also from its institutional memory. Sad - isn't it? It is precisely for this reason that I was most pleasantly surprised when our colleague Slavko Splichal organized some years ago (in 2005) in Fiesa the international round-table on 'The MacBride Report 25 Years Later'. A very nice way to mark this anniversary. The written contributions prepared for it, and the debate truly impressed me and, moreover, convinced me that all the endeavour to produce the Report, and the struggle around it, were after all not in vain. 